\title{
The Decline of Architects: Can a Computer Design Fine Architecture without Human Input?
}

\author{
Joanna Kołata and Piotr Zierke *(1)
}

Faculty of Architecture, Poznan University of Technology, 61-131 Poznan, Poland; joanna.kolata@put.poznan.pl

* Correspondence: piotr.zierke@put.poznan.pl

Citation: Kołata, J.; Zierke, P. The

Decline of Architects: Can a

Computer Design Fine Architecture without Human Input? Buildings 2021, 11, 338. https://doi.org/10.3390/ buildings 11080338

Academic Editor:

Derek Clements-Croome

Received: 16 June 2021

Accepted: 4 August 2021

Published: 6 August 2021

Publisher's Note: MDPI stays neutral with regard to jurisdictional claims in published maps and institutional affiliations.

Copyright: (c) 2021 by the authors. Licensee MDPI, Basel, Switzerland. This article is an open access article distributed under the terms and conditions of the Creative Commons Attribution (CC BY) license (https:/ / creativecommons.org/licenses/by/ $4.0 /)$.
Abstract: Architects are required to have knowledge of current legislation, ergonomics, and the latest technical solutions. In addition, the design process necessitates an appreciation of the quality of the space and a high degree of creativity. However, it is a profession that has undergone significant changes in recent years due to the pressure exerted by the development of information technology. The designs generated by computer algorithms are becoming such a serious part of designers' work that some are beginning to question whether they are more the work of computers than humans. There are also increasing suggestions that software development will eventually lead to a situation where humans in the profession will become redundant. This review article aims to present the currently used, implemented, and planned computer technologies employed in the design and consider how they affect and will affect the work of architects in the future. It includes opinions of a wide range of experts on the possibility of computer algorithms replacing architects. The ultimate goal of the article is an attempt to answer the question: will computers eliminate the human factor in the design of the future? It also considers the artificial intelligence or communication skills that computer algorithms would require to achieve this goal. The answers to these questions will contribute not only to determining the future of architecture but will also indicate the current condition of the profession. They will also help us to understand the technologies that are making computers capable of increasingly replacing human professions. Despite differing opinions on the possibility of computer algorithms replacing architects, the conclusions indicate that, currently, computers do not have capabilities and skills to achieve this goal. The speed of technological development, especially such technologies as artificial superintelligence, artificial brains, or quantum computers allows us to predict that the replacement of the architect by machines will be unrealistic in coming decades.

Keywords: decline of architects; future of designing; computers control; algorithms; artificial intelligence

\section{Introduction}

The architectural profession combines science, engineering, and art. It is an occupation that requires knowledge of current legislation, ergonomics, or the latest technical solutions and the need to assess the quality of space and creativity. However "the profession of the architect has never been stable" [1] (p. 8). The role of architects has evolved over the years and while they are still responsible for the quality and shaping of the space and "for the visual appearance of buildings and structures" [2], "demiurges [... ] controlling the whole creative processes, consistently seeking to achieve a goal" [3] (p. 35), this profession can be also "characterised by a continuous transformation of its conditions and characteristics" [1] (p. 8). Architects are right now "the so-called mediators between different professions and they have to monitor the progress of the project from its initial stages onwards" [4] (p. 41). Over past few years they are also "challenged to take a public role, share their knowledge of space, their imagination of possible futures, and their intuition to grasp and affect a specific site or condition. The architect not only draws the lines and limits of space but also deals with the world and the people in it." Recently "new techniques of communication and modeling [ ... ] extensively affect the architect's work" [1] (p. 7). This 
is caused, among other things, by the development of information technology, especially BIM (building information modeling), BLCM (building life cycle modeling), parametric design, or AR (augmented reality). By offering architects new design possibilities, they influence space. At the same time, they make work faster and easier in many aspects. However, questions arise as to whether computer algorithms are not starting to interfere too much in the creative process of architects and whether projects created as a result of this cooperation are not becoming more works of computers than humans. At the same time, there are concerns that the trend of computer programs taking over architects' work will continue and, eventually, a human being will become redundant in this profession.

This is a scoping review article. It aims to present current, implemented, and planned computer technologies used in the design and discuss how they affect and will affect architects' work in the future. Due to the nature of this article, a research query was conducted on the opinions of a wide range of experts. The selection of statements was based on the occupational criteria of the commentators. These include architects, scientists, developers of computer aided design software, but also writers, journalists, and even philosophers. The authors wanted to select opinions that represent different approaches to the possibility of replacing architects by computer algorithms. These comments, due to their different attitudes towards the aforementioned possibility are presented in the "Yes" and "No" subsections of this paper. The selection of opinions was also based on the different reasons that guided the commentators in forming their judgements, e.g., the development of particular technologies or limitations affecting computers and algorithms. The selection was not limited to the most recent commentaries, but the older ones from early computer development were also cited. The selection of opinion makers was focused on their experience and prestige. As a result, among representatives of scientists dealing with the described problem in their research work, opinions of professors predominate. Architects are mostly represented by a group of recognised and awarded designers, including those from well-known design studios. Design aid software manufacturers are dominated by representatives of leading companies from all over the world. This manuscript also contains statements of less known professionals. However, in the opinion of the authors, they contain important information on the described subject, which shows other, sometimes not obvious, points of view and enables a look at the described topic from a different perspective.

In the following part of the article, the obtained data are synthesised and an attempt is made to identify the patterns appearing in them. This will help to define the skills that computer algorithms would need to acquire in order to theoretically be able to replace architects.

The ultimate goal of the manuscript is an attempt to answer the question: will computers eliminate the human factor in the design of the future?

The answers to questions posed in this manuscript will contribute not only to determining the future of architecture but will also indicate the current condition of the profession. They will also help us to understand the technologies that are making computers capable of increasingly replacing human professions. Therefore, the problem described is multifaceted, and its complex character touches upon IT issues and sociological and even philosophical matters presented in this article.

\section{Current Capabilities of Computers in Architectural Design}

The initial use of the computer in architectural design was limited to replacing the drawing board, as exemplified by the widely used AutoCAD software. Dedicated CAD (computer-aided design) software was undoubtedly a great improvement on tedious manual work. Nowadays, there are more advanced programs such as ArchiCAD, which allow block design using predefined building components such as walls and ceilings. The design software continues to improve. Autodesk's Dreamcatcher is supposed to be the next generation of CAD. It is "a generative design system that enables designers to craft a definition of their design problem through goals and constraints. The system generates thousands of design options that meet specified goals, allowing designers to explore trade-offs between many alternative approaches and select design solutions for 
manufacture" [5]. The MaRS Innovation District office and research building in Toronto was designed using Dreamcatcher software. The design of the building was generated based on the needs and wishes of future users. "Software made it possible to take all of these factors into consideration to find a set of optimal options that satisfied as many criteria as possible" [5]. The benefits of generative design and examples of building forms created with this technology in Kiruna, Sweden, were presented among others by Jani Mukkavaara and Marcus Sandberg [6] (pp. 8-16).

System extensions and the introduction of the third dimension into CAD software have made it possible to integrate the various elements of a project into one thing. In recent years, BIM software, which uses "a modelling technology and associated set of processes to produce, communicate and analyse building models" [7] (p. 13) have been gaining popularity. Denis Neely noted that "design professionals are moving to BIM three times faster than the transition from hand drawing to CAD" [8], and in 2011 "BIM use reached the 50\% mark among design professionals" [9] (p. 6) These programs significantly improve the work of architects, but professors Wojciech Bonenberg and Oleg Kaplinski also noted that BIM unexpectedly raises an architect's professional prestige [10] (p. 9). For instance, "the Sichuan Provincial Architectural Design and Research Institute used AECOsim Building Designer's BIM advancements to enhance information exchange among disciplines and ensure timely collection, update, management, and data application. The software enabled the institute to shorten the project period by $60 \%$, reduced design errors by $80 \%$, and increased design depth by 50\%" [5]. Professors Oleg Kapliński and Wojciech Bonenberg consider the implementation of BIM technology (especially BIM as a process) and integrated project delivery (IPD) as "important elements conducive to the integration of architectural and engineering activities" [11] (p. 5), fundamentally affecting the work of architects in the future.

At the same time, parametric design programs are appearing, which enable the creation of ready-made structures based on parameters proposed by architects. They treat "the geometric properties of the design as variables", resulting in a design that consists of "relationships that are maintained between the various elements of the composition" [12] (p. 1). "By far the most widely used parametric design software is "Grasshopper" developed by the David Rutten for Robert McNeel Associates and first released in 2008" [12] (p. 5). Grasshopper is a platform closely integrated with Rhinoceros-McNeel's 3-D modeling tool, "to deal with this generative algorithms and associative modelling" [13] (p. 4). It also enables integration with sensors and software based on machine learning and artificial intelligence technologies. [14] (pp. 6-7). Therefore, it should come as no surprise that an increasing number of projects are based on this technology, which can be seen, for example, in the design of offices by Frank O. Gehry or Zaha Hadid. In 2021, a building design was presented by a Japanese architectural studio called Laboratory for Explorative Architecture and Design (LEAD) that was entirely generated by a computer program based on an algorithm prepared by the studio [15]. In addition to improving the work of designers and facilitating the design of complex, sculptural building forms, parametric design has had a significant impact on the architecture of cities such as Dubai, Doha, and Bilbao.

Currently, the most hopeful developments in computer-aided design are in "the fields related to machine learning (ML), including data mining, machine vision, computational statistics and other sub-fields of artificial intelligence (AI)" [16] (p. 14) as well as mobile robotics and computerisation in manual tasks. Frey and Osborne note that "machine learning algorithms running on computers are now, in many cases, better able to detect patterns in big data than humans" [16] (p. 16), which is exemplified by the aforementioned generative design technology, but they then admit, that "robots are still unable to match the depth and breadth of human perception" [16] (p. 24). Besides, as Yaser S. Abu-Mostafa notes, "Machine learning does not create information; it gets the information from the data. Without enough training data that contain proper information machine learning will not work" [17] (p. 81). 
When it comes to AI, "in 2016, Google in the US developed the artificial intelligence (AI) applied in the field of graphic design" [18] (p. 2) called Alpha GD, which Wu Shan perceives as "a great threat to people engaged in graphic design" [18] (p. 2). Professor Duc Truong Pham notes "that there is a wide range of techniques which are capable of enhancing traditional CAD systems with advanced reasoning abilities thus increasing their prospect of being tools for intelligent design" [19] (p. 24). These include, among others: deep knowledge, non-monotonic, qualitative and geometric reasoning, uncertainty handling, and object-oriented representation [19] (pp. 15-24). Despite the increasing use of artificial intelligence in the construction industry $[20,21]$ and design, as well as the aforementioned concerns about the future role of AI programs in design process, so far "it can only imitate the existing board, but cannot achieve independent innovation." [18] (p. 2).

In summary, computers and computer programs are increasingly influencing the work of architects. Increasingly sophisticated algorithms are being developed which can generate the forms of buildings or help to make decisions about, for example, their functional scheme or construction. However, these technologies are still not able to replace architects. One could even say that they are nowhere near it. This is supported by Frey and Osborne, who find that the level of complex perception and manipulation skills, creativity, and social intelligence necessary to design buildings [16] (p. 27) are tasks beyond the capacity of current computers. But will they be able to replace architects in the future?

\section{Will Computers Replace Architects?}

Eight years have passed since Carl Benedikt Frey and Michael A. Osborne estimated the probability of the architectural profession being replaced by computers in the next few decades at only $1.8 \%$ [16] (p. 58). In the past, however, different points of view have clashed, assuming, on the one hand, the 'death' of the architectural profession, and on the other, the impossibility of its replacement by machines. Let us consider how others-architects, planners, sociologists, philosophers, architectural software developers, architecture critics, or visionaries-view this issue.

\subsection{No}

It appears that among predictions concerning the possibility of computers replacing humans, skeptical opinions prevail when it comes to architectural design. The concerns are related primarily to the lack of perception and feeling of the world through the senses, which those expressing them believe are an indispensable element of design. The famous Swiss architect Peter Zumthor believes that: "The strength of good design lies in ourselves and in our ability to perceive the world with both emotion and reason. A good architectural design is sensuous. A good architectural design is intelligent" [22] (p. 65). In his essays on architecture, he points out that design is constant cooperation between feelings and reason. Each design is an expression of fleeting feelings, longing, desires to which the architect is subject and which are only creatively transformed by reason. Design, therefore, stems from inspiration but is also subject to change at every stage and as a result of each line drawn. The perception of the design and consequently the project itself changes as a result of the design process. It causes joy and excitement but is also the result of these feelings, which he compared to the effects of a drug [22] (p. 21). A similar opinion is expressed by Finnish architect Juhani Pallasma, who unambiguously claims that the lack of feelings, the inability to guess human emotions, or the possibility to create is the obstacle that will prevent architecture from ever being fully automated. Interestingly, he considers the perfect and repetitive execution of tasks by computers to be the biggest drawback in this respect. He believes that "creative work needs space to move. Too much precision is not good for creativity" [23]. This obstacle to designing is also noted by Andy Smith, Director, Product Management, Building Solutions, Bentley Systems, who "believes that computers are very good at solving specific tasks, such as engineering calculations, and can even make some quality assessments. But in the near future, computers will not be able to combine the 
five human senses and really understand the poetry of emotion that is a building" [5]. Interestingly, Andy Smith's opinion is quite common among representatives of design aid software producers. British Autodesk vice president Pete Baxter responsible for its architecture, engineering and construction operations in Europe, Asia and the Middle East believes that "technology won't destroy the profession, but it will, democratise it. There's a paradigm shift now: the one-man architect working from home with a bright idea now has access to an infinite amount of computing power in the cloud. That means a one-man designer, a graduate designer, can get access to the same amount of computing power as these big multinational companies. So suddenly there's a different competitive landscape. [ ... ] The architectural profession absolutely will still exist. [ ... ] I think what's happening is we're getting a more collaborative approach. But ultimately somebody still makes the decision" [24]. Autodesk CEO Andrew Anagnost, adds that "Each era of automation, from the first industrial revolution through the present digital era, has created more jobs, not less. Why should we assume the new machine age-the new era of automation-will be any different?" [25].

The Australian philosopher Elizabeth Grosz also draws attention to another characteristic that an architect should have, that is the capacity "for exploration and invention, in recognition of the roles of architecture and knowledge as experimental practices" [26] (p. 171). It is a capacity in which the architects, looking at the world, "try to enhance what seems to be valuable, to correct what is disturbing, and to create anew what we feel is missing" [22] (p. 24). Thus, they react to the constant changes of the context, trying to capture the beneficial elements from it and constantly correcting those that are unfavorable. It appears that design, which to such a large extent is the result of feelings that hinder the designer and influence the shape of the building, is an insurmountable obstacle for machines. What is more, it seems to be an extremely difficult, although possibly simpler, task to react to changes in the context or design trends.

Artificial intelligence is a technology whose future development and refinement make it possible to consider the actual replacement of architects by computers. However, it is worth noting the opinions that "computers don't come up with innovations. People do. Even the computer itself is a human innovation. [ ... ] A.I. facilitates the idea. It makes the idea possible. However, it doesn't come up with the idea in the first place. [ . . . ] The artificial intelligence itself cannot exist without the ingenuity of the people that created it. A.I. needs maintenance and updates, otherwise, it becomes outdated in its own time" [27]. The current quality of artificial intelligence, as well as the readiness of computers to perform very complex tasks related both to the design itself and to relating the designed buildings to the surrounding context, causes many people to doubt the possibility of developing it in such a way that it would be able to replace humans in particularly complex fields such as architecture. Polish architect Aleksandra Wasilkowska shared the following excerpt from her conversation with the so-called Cleverbot—an intelligent computer program that passed the Turing test:

"- What is the architecture of the 21st century?

- People are close to revolt.

- What can it be?

- The song of angry men.

- What will it be?

- I don't know, because I won't be alive then" [28] (p. 356).

The answers are perhaps disturbing in the context of the social role of architecture. However, they may just as well sound rather random and, in this case, indicate that the intelligence of modern computers still has a long way to go before they can not only design a building but create architecture. It is now more akin to the cryptic words spoken in ancient Greece by Pythia, which were ambiguous, confusing, and unclear, and the priests had to give them the correct interpretation. Overstating the role of design software while downplaying the role of architects is pointed out by Reinier de Graaf, an architect, architectural theorist, urbanist, and writer, who states that "computer programs have 
been developed that allow you to design boxes in an increasingly sophisticated way: Microstation, AutoCAD, Rhino, Revit, BIM [ ... ] However, the final form is still given to the box in Excel" [29] (p. 84).

The growing role of artificial intelligence is also noted by the authors of the "Technology and Innovation Report 2021" who believe that this technology "can also use modelling and a lot of data to make predictions that mimic human intelligence. This alters the nature of jobs by increasing or reducing the number of tasks. Some jobs will disappear, but others will emerge-such as those requiring empathy, inventiveness and ethical judgements that need to be made by humans" [30] S. 38. It seems, therefore, that according to the authors of the report, the profession of architect, which requires creativity and ingenuity, is not threatened, at least for now. Currently, technology has a great influence on tools used by architects and thus indirectly influences architecture, and although many contemporary design solutions are possible due to technological progress, "technology doesn't have an impact on thoughts, ideas or decisions" [31] (p. 194). This stance is echoed by Reinier de Graaf, who believes that "the information revolution-the turning point of our time-has not changed buildings, only the way we use them, so its impact on architecture is limited. By breaking the link between buildings and what happens in them, digital technologies [ ... ] do not elevate the status of architecture; they actually lower it" [29] (p. 81).

Another problem that currently prevents computers from taking over the tasks of an architect is the poor relationship between computers and humans and the lack of interaction. This seems to be confirmed by the words of German architect Walther Gropius, who already in the 1940s said that "architecture requires strong convictions and leadership skills. Its form cannot be determined by clients or opinion polls. The results most often boil down to a desire to preserve what everyone already knows very well" [32] (p. 128). Gropius himself, moreover, believed that "the artist is the prototype of the 'complete' man; his freedom and independence are relatively intact. Intuitive sensing should be the antidote to mechanisation gone too far, ideally working to bring life back into balance and give a human dimension to machine influences [ ... ] The contribution of the creative artist, whose art can more fully express the visual as well as the human appeal of planning, is essential" [32] (pp. 218-219).

People who express their opinions on the future of the architectural profession are undoubtedly aware of the continuous and unstoppable development of computer technologies, which will have an increasing impact on the design process. At the same time, they very often exclude the complete takeover of the architect's tasks, postulating that computers will be an increasingly effective complement to the architect's skills, allowing for more efficient, faster, and more accurate work. Dale Sinclair, Director, Architecture, Technical Practice, AECOM, agrees that "by automating aspects of the design process, such as creating multidisciplinary digital libraries that contain fabrication-ready information, more time can be spent on the design effort that makes a building unique in response to the client's brief and relevant to its environment" [5]. He compares the art of design to music, in which "musicians have embraced new instruments from the electric guitar to synthesisers and onwards to automated composing tools, as delivery of their outputs has shifted from albums to streaming. Yet the role of the composer remains unaltered" [5]. There are also claims that despite the significant developments in computer technology and artificial intelligence, "it doesn't have to mean that it causes job losses. As with any new technology, it's likely that A.I. will create just as many jobs as it displaces" [27].

There is another indication that the rise of computer technology will not result in the end of the architectural profession. As reported in the National Council of Architectural Registration Boards' annual survey, the number of licensed architects has grown in the USA by $1 \%$ from 2018 and by 10\% from 2010 [33]. "While the number of architects licensed in the United States has risen over 13\% in the last decade, the total U.S. population has risen just $7 \%$, according to data from the U.S. Census Bureau" [34]. There is even more significant growth in the number of architects in Europe. Between 2008 and 2018 "the total number of architects has grown by 24\%" and "reached in 2018 the number of 562,000" [35] (p. 4). 
Although the above data does not cover the whole world, it shows that in highly developed countries, where e.g., the use of BIM technology is mandatory in a large proportion of projects and the percentage of construction companies that use BIM ranges from $20 \%$ (Austria) to 73\% (United Kingdom) [36], the number of architects is increasing. This is despite the fact that in recent years there has been a rapid development of design support technologies like BIM [37], which originated in the 1980s [36].

\subsection{Yes}

Despite the prevailing view that the computer will not—at least for the time being-be able to replace people in the field of architecture, there are, however, also those who predict a more or less imminent end to the architectural profession. As early as 1943, Walter Gropius noted that "more than $80 \%$ of all American buildings are erected without the involvement of an architect" [32] (p. 112). Therefore, in theory, an architect is not needed to design buildings or even fine architecture. Many famous designers never received an architectural education. These include Mies van der Rohe, Le Corbusier, Louis Sullivan, Peter Zumthor, Luis Barragán, Buckminster Fuller [38], and Tadao Ando [39] (p. 131). Moreover, in some countries, e.g., Ireland, the opening of an architectural design studio depends on the payment of appropriate insurance, not on the possession of an architect's diploma. De Graaf also cites the example of the automated architecture of housing estates in the GDR, where "architecture ceased to be a matter of individual talent (and thus the exclusive preserve of the lucky few blessed with this gift), it came down to the mastery of certain know-how, from an innate skill to an acquired one. [ ... ] East Germany [ ... ] eliminated the need for the architect as a great builder and turned the entire surface of the country into a great exhibition of achievements made possible by his absence" [29] (pp. 61-62).

Despite the turbulent history of building design, the architectural profession continues to exist and, despite the onslaught of information technology, it seems safe for the time being. Nevertheless, some architects like Krzysztof Ingarden believe that "further technological development, in particular the automation of design and construction processes, may go so far that it will be possible in the near future to replace man by machines, both at the design and construction stage" [40] (p. 23).

Ian Keough, CEO of HYPAR in his foreword to Randy Deutsch's book Superusers: Design Technology Specialists and the Future of Practice links the future of the architecture profession to so-called superusers, who believe that "much of what we do in architectural practice can and should be automated, but they work in a profession which has its roots in an artistic tradition spanning hundreds of years. This tradition assumes [ . . ] erroneously, that the act of 'design' is irreducibly human" [41] (pp. xi-xii). Admittedly, Keough does not say that computers will be able to completely replace humans, but he doesn't rule it out either. Randy Deutsch agrees with him and says "that the architecture profession and design industry will look radically different by 2030; and design technology specialists-a particular high-performing, high-functioning, highly connected, and highly motivated vocal minority here called Superusers-represent the near future of our industry" [41] (pp. xix-xx).

The greatest hopes for the development of design capabilities by computers are related to the evolution of artificial intelligence, especially the emergence of strong AI, also called artificial general intelligence (AGI), which, according to some researchers, will lead to the creation of the so-called artificial superintelligence. "As estimated by recognised AI scientists such as Kurzweil and McCarthy, once the strong AI is achieved, it will not take a long time for them to surpass human intelligence. The key point of strong AI is that it will be able to learn by itself, and therefore upgrade itself on its own, without any instructions from human agency" [42] (p. 18). Computers would then gain something akin to a human brain, although currently, the human organ is still full of mysteries. A better understanding of its properties may in the future be used to create computer programs that not only work on algorithms prepared by humans but also create them themselves. Wasilkowska gives 
the example of work on the BMI (brain-machine interface) and suggests that "if we perfect the method of a more precise mapping of our thoughts on the basis of brain activity, we will be able to transfer this information to the receptors of mechanised and intelligent architecture. Maybe knowledge about our state of consciousness combined with robotics could in the future allow for a wider definition of architecture" [28] (p. 357).

It seems that without achieving the advances in the development of computer algorithms described above, it will be impossible to eliminate the work of architects even though technologies are now emerging that allow the computer to perform some of the architect's tasks. They are becoming increasingly visible in reading the context for future buildings and suggesting very preliminary blocks, devoid of actual architectural expression, which nevertheless meet spatial and legal requirements. Their further processing remains the domain of architects. Nevertheless, there are claims that "applied mathematics can decipher the architectural context of space" [43] (p. 88).

Describing the latest technologies designed to make architects' work easier and faster, it is worth mentioning that the company Flux has prepared a modeling tool in which parametric buildings are automatically adjusted to the site constraints and official requirements resulting from the spatial context. This creates design "'building seeds' which generate different buildings in various contexts" [44]. "In the software they managed to automate the import of building and urban codes, therefore on the basis of contextual information the application is also able to generate "buildable envelopes on the site'" [45] (p. 113). Although the object generated in this way fits in with the surroundings in terms of scale and mass, it still cannot be said that the program has succeeded in shaping architecture. Dana Nidal believes "that AI will be less likely to replace architect, and in terms of architecture practice it will provide new methods that adopt to future demands of people" [46] (p. 2).

Certainly, the growing computational possibilities in the future will make it possible to adjust the urban planning parameters so that they meet one of the most important criteria for the client, i.e., maximum return on investment. Mechanisms of learning or remembering may consequently allow for a preliminary rejection of such solutions, which are currently considered 'pathological' despite meeting formal requirements. This means that computer programs could make it possible to create better architecture coherent with the environment, independent of human weaknesses and temptations, e.g., financial ones. The preliminary building forms created in this way could also become the basis for further design processes that would be performed by computer software, especially for parametric or generative design. After all, it is already possible to create multiple variant concepts by generating sequential spatial sequences without requiring hours of work by a team of people. Nevertheless, the final decision as to the choice of the final version of the building's architecture that best meets the requirements of the spatial order, as well as the expectations of the client and the users, is up to the architect at the moment.

However, developments in AI may change the situation described above. Some architects and architecture critics believe that parametric design already takes away part of the creative process from the architect, sometimes leaving the human only to choose the best option proposed by the algorithm. Reinier de Graaf mentions this when he says that "by partially ceding the creation of form to computers, the antibox has elevated the production of extravagant shapes beyond any imaginable limits. What was still a conscious reflection on the concept of form in the early boxes has turned into a lottery. The question of authorship has become relative-since creation has been taken over by algorithms, the main joy offered by the antibox is the surprise it gives its designers" [29] (pp. 94-95). If he is right, then we are closer to replacing architects with computers than many pessimists think. This point of view is moreover echoed by Randy Deutsch AIA, LEED AP, Associate Director, Graduate Studies, School of Architecture, University of Illinois Urbana-Champaign, who notes that current "generative design has its own aesthetic, and for many it's is an acquired taste [ ... ] Here, there is nothing for us humans to do but to accept the aesthetic of optimisation (however defined by those providing the computer input) because ostensibly 
what the machine generates is perfect-and it is up to us humans to allow the aesthetic to grow on us" [5].

The ease with which algorithms can generate further variants can be alongside or completely outside of the usual patterns to which the machine is not attached in any way. Thus, the probability of an original result is increased, at least early in the computerdesigner's career. The competition and the number of objects created so far in each of the considered architectural scales are so large that it is difficult for the author to create original solutions all the time, which is currently a prerequisite for success in this industry. The computer can help solve this problem, but in some cities, the extravagance level of modern buildings is often so high that architecture hitherto perceived as 'boxy' becomes, according to De Graaf's aforementioned 'antibox' claim, a form of denial of previous achievements. Computers that will be deciding on architectural forms in given locations in the future will have to know the difference between acceptable and sometimes desirable originality of form and a block that does not fit into the context and introduces spatial chaos. Legal issues also remain, and who would actually have the copyright to the computer-generated designs- the owner of the software license, its manufacturer, or the software itself.

For now, it seems that the acceptable participation of the computer in the design process concerns automated processes that merely assist the architect but leave the architect with the final decision on the architecture. Allowing algorithms to be more intrusive in the design process will require a change in people's mindsets and readiness to accept such generated architecture. However, we cannot fool ourselves into thinking that architects these days only create good designs. Reinier De Graaf gives a very harsh assessment of the quality of most buildings currently under construction. He notes that "most of the buildings being erected today are stunning in their indescribable ugliness. They make up an endless collection of cheaply made buildings, harnessed to an endless bloodless competition to earn the highest possible return on the lowest possible budget" [29] (p. 25). It is possible that the acceptance of the new, computerised aesthetics will not be such a big problem for human buyers, especially since the final approval of the design, at least for now, is made by people-the investor and officials.

\section{Theoretical Requirements for Computers to Replace Architects}

According to Frey and Osborne, computers that are to replace humans in the future must be able to perform tasks that include simulating human perceptivity, human movements (manipulation tasks), must be able to handle creative intelligence tasks and social intelligence tasks [16] (pp. 24-26). While the ability to simulate human movements is not necessary to replace architects in design, the other skills seem essential. The senses enable architects to feel their surroundings. Without the senses, the concept of genius loci would not exist, i.e., the idea of the spirit of a place, which is expressed by "giving individual quality to particular places-objects, houses and complexes, cities, gardens and whole landscapes" [47] (p. 228). The senses are also essential to be able to experience beauty which is an indispensable component of architecture. Computers, that have no senses, could be capable of designing buildings but it is unlikely that they would ever be able to consciously design works of architecture.

Technologies that deal with computer perception have been under development for many years and, as a result, there are algorithms created that enable facial and voice recognition or that make it possible, still in a limited way, to communicate with devices. The latter group includes i.e., the so-called virtual assistants such as Siri developed by Google, Alexa by Amazon, Cortana by Microsoft, S Voice by Samsung and Google Assistant. In the field of architecture and urban planning, algorithms are now becoming better at dealing with such tasks as object recognition and categorisation, 2-D and 3-D modeling, or tracking and visual servoing. There still remains a challenge to properly understand the spatial context and draw conclusions to be able to create a design. It seems that improving the ability to recognise and characterise the environment is not a big difficulty at this point, as it most likely only requires improving the existing algorithms, increasing the 
power of processors and the amount of memory to collect enough spatial data. The real issue, still unsolved, remains the lack of sensitivity of computers to beauty. The above is a complicated task as the concept eludes measurable criteria and, at this stage, there is no mathematical formula that could be used to enable the computers to take over.

Another necessary requirement that would enable replacing architects with computer algorithms is to design creative intelligence to translate sensations and experiences into the language of architecture. Designing is, after all, an act of creation. While one can see increasing progress made in the field of artificial intelligence in such areas of art as literature, painting, and music [48]. "AARON, a drawing program, has generated thousands of stylistically-similar line-drawings, which have been exhibited in galleries worldwide. Furthermore, David Cope's EMI software composes music in many different styles, reminiscent of specific human composers" [16] (p. 26). It is still rather a collaboration between a machine and a human being than independent action. John Spacey believes that to end this dependence in the future, it will be necessary to develop a superintelligence with elements of consciousness such as intentionality, which theoretically can be developed with the use of recursive, self-improving program [49]. Self-adaptive systems will likely do very well in the field of architecture because they are inherently creative, their adaptations are unique and useful because of the unique situation to which they respond [50] (p. 10). Superintelligence is "foreseen as the last step of AI technology, it is considered as the milestone of the technological singularity in the future. At these further steps, it might be possible for artificial intelligence to develop an advanced form of artistic creativity" [42] (p. 77). However, Frey and Osborne find that "generating novelty is not particularly difficult. Instead, the principal obstacle to computerising creativity is stating our creative values sufficiently clearly that they can be encoded in a program [ . . ] Moreover, human values change over time and vary across cultures [ ... ] Thus, even if we could identify and encode our creative values, to enable the computer to inform and monitor its own activities accordingly, there would still be disagreement about whether the computer appeared to be creative" [16] (p. 26).

This also raises the question, which coincides with the concerns of architects Peter Zumthor or Juhani Pallasma, expressed in previous chapters, that "if there is no initial intention to express a feeling, an aesthetical point of view, or any personal statement per se, can we still mention the existence of an artistic creativity" [42] (p. 72)? This is an important question, because even when computers will be able to design buildings on their own, there may be voices saying that this is still not architecture, since it was created without emotions. However, Deniz E. Kurt believes that "despite the absence of an initiative emotional expression of the maker, the flow of affect will occur through a bottom-up perspective, and the 'feeling' of an artwork will be shaped through the emotional attachment of the human spectator" [42] (p. 73). Thus, in such a case, "AI is the actor who generates the artworks by using its own interpretation" [42] (p. 74). "Hence, for AI artworks to be recognised as artistically creative, they should correspond to the human taste of aesthetics and human emotions. The absence of human emotions in a machine is an intrinsic feature that gives the aura to the artwork of that machine" [42] (pp. 75-76).

Questions also arise about the copyright of designs created by computer programs [42] (p. 58). However, it must be acknowledged, that controversy is also associated with projects created by people. Peggy Deamer in her works points out many problems concerning employment in architectural firms. She also notes that architects are responsible for an important, but limited, part of a building's design. "In architecture, unlike the other arts no one person actually makes the object. Not only is there the significant distinction between designer and builder, or the multi-layered group of designers in an office, but the designers/manufacturers of the myriad of products used for a project bring the history of their own making with them" [51] (p. 17). Another issue is the multi-discipline nature of building design, where only part of the process falls to architects, but there are also structural engineers, installation designers, road engineers, etc. This contributes to the complexity of design and makes it difficult for computer algorithms to take over all of their 
skills. Nevertheless, design is a process that requires social intelligence. In this case, it is used, among other things, during the usually lengthy arrangements and negotiations with the client. They take place not only before the design work begins. Instruction changes occur even at an advanced design stage and are often necessary even during construction. Assuming that a computer algorithm would be responsible for the entire design process, which would eliminate the experts, technologists, and collaborators working with architects, social intelligence would still be indispensable for the reasons above. This view is supported by Frey and Osborne, who noted that computers that would design buildings must be able to talk to clients, have negotiation skills, and perhaps manage human resources [16] (p. 27). Andy Smith, Director of Product Management, Building Solutions, Bentley Systems, agrees with this sentiment, saying that the architect, after all, "needs to communicate the design intent to the client, explain why he or she chose certain things, and then evaluate the responses of the client's emotions and business sense to the design. That is a human interaction that needs to happen" [5]. In addition to negotiation skills, human social intelligence includes skills such as persuasion and caring [16] (p. 26). While computers "can now reproduce some aspects of human social interaction, the real-time recognition of natural human emotion remains a challenging problem, and the ability to respond intelligently to such inputs is even more difficult. Even simplified versions of typical social tasks prove difficult for computers" [16] (pp. 26-27).

At this point the problem of ethics also arises, which means the ability to take actions focused not only on a specific goal, such as making money or completing a project at any cost, but also responsibility for the users of the designed building and its impact on the environment. Benjamin Kuipers believes that "artificially intelligent creatures (AIs) [ ... ] may increasingly participate in our society over the coming years. In effect, they may become members of our society" [52] (p. 98). Ronald C. Arkin and Alan R. Wagner make this eventuality contingent on robots recognising such moral emotions as dignity, guilt, trust, or even the ability to deceive. [53] (pp. 1-46). And although the basic laws of robotics were defined by Isaac Asimov as early as 1950. [54], and work on so called roboethics is now being undertaken by research institutions $[55,56]$, robots and computer programs that control them are still unprepared to function in society. Kuipers believes that "the problem of providing robots with morality and ethics [ ... ] draws on many different research threads in cognitive science, artificial intelligence, and robotics. These and other problems to be solved are difficult, but they do not appear [ ... ] to be unsolvable. In the visible future, robots and other AIs are likely to have sufficiently useful capabilities to become essentially members of our society" [52] (p. 103).

As with creative intelligence, the greatest hopes for developing this technology are specifically related to the development of artificial intelligence. However, current estimates suggest that full human brain emulations should be possible before mid-century [57] (p. 81). The development of computer-aided design tools, as well as technologies that are likely to be developed in the future, are shown in Table 1. 
Table 1. Development of software and technology for computer design.

\begin{tabular}{|c|c|c|}
\hline Timeline & Type of Software/Technology & Software/Technology Capabilities \\
\hline \multirow[t]{2}{*}{ Past } & 2D Designing Software & drafting software to replace freehand drawing \\
\hline & 3D Designing Software & $\begin{array}{l}\text { software enabling the creation of spatial structures used to } \\
\text { generate particular parts of a design study }\end{array}$ \\
\hline \multirow[t]{8}{*}{ Present } & Parametric Design & $\begin{array}{l}\text { designing 3D structures and patterns following given } \\
\text { parameters }\end{array}$ \\
\hline & Generative Design & results-oriented design \\
\hline & Building Information Modeling & $\begin{array}{l}\text { 3d modeling related to building model production, } \\
\text { communication and analysis kit }\end{array}$ \\
\hline & Building Life Cycling Modeling & modelling various aspects related to the life cycle of a building \\
\hline & Augmented Reality & transferring virtual projects into real space using dedicated tools \\
\hline & Neural Networks & forecasting phenomena based on initial data \\
\hline & Machine Learning (ML) & collecting data and learning to use it under human supervision \\
\hline & Artificial Intelligence (AI) & $\begin{array}{l}\text { advanced machines and software based on neural networks } \\
\text { and machine learning capable of solving complex problems }\end{array}$ \\
\hline \multirow[t]{3}{*}{ Future } & Active Augmented Reality & real-time creation of spatial models in augmented reality \\
\hline & $\begin{array}{l}\text { Artificial General Intelligence (AGI)/ } \\
\text { Strong Artificial Intelligence (SAI) }\end{array}$ & $\begin{array}{l}\text { advanced machines and software based on neural networks } \\
\text { and machine learning capable of solving complex problems }\end{array}$ \\
\hline & Artificial Super Intelligence & $\begin{array}{l}\text { highest form of computer intelligence that will enable the } \\
\text { replacement of humans by machines, including architecture }\end{array}$ \\
\hline
\end{tabular}

\section{Conclusions}

The material presented in this manuscript shows recent developments in computer technology and their impact on the work of architects. It also provides deliberations of a wide group of experts on the future of that profession. It represents a rare group of papers that collects and interprets information about the impact of a wide range of technologies on the work of architects, and attempts to predict how this development will affect the profession in the future. Its novelty also lies in its effort to define requirements that could theoretically contribute to the elimination of architects' work. Although this paper is about the future, and thus cannot provide definite answers, it allows us to extract information that is certain and that may help us understand the future of this problem. A summary of this information is presented in the following items.

(a) The architectural profession, unlike some other occupations now being displaced by computer algorithms, requires wide-ranging competencies and skills, such as creative and social intelligence. Currently, computers do not have such capabilities, and thus do not have the potential to replace the work of architects.

(b) The future will see further development of computers and technologies such as machine learning, artificial intelligence, superintelligence and most likely others as yet undefined.

(c) The current development of computer technologies is not aimed at replacing architects, but at supporting, facilitating and speeding up their work. Therefore, it is difficult to expect that technologies which could replace architects' work will appear in the near future.

(d) People who accept the possibility of computers replacing the work of architects in the future, associate this eventuality with the development of such technologies as artificial superintelligence. It may be that the introduction of fully self-learning software will come closest to the goal discussed above, but it may also simply bring further, even more advanced improvements to the work of architects that will continue to be controlled by humans. 
(e) Currently, it seems that occupations requiring creativity and social skills could be eliminated only as a consequence of creating an artificial brain with capabilities not inferior to the human organ.

(f) Although research on the human brain is now extensive, and we have increasing information about how it works, a complete understanding of its capabilities and limitations is beyond the reach of modern scientists. Without learning these principles and translating them into the language of computers, it is difficult to think of replacing architects with machines. Computers lacking the aforementioned skills or the ability to interpret information generated by the senses would, therefore, perhaps be capable of designing buildings but it is unlikely that they would ever be able to consciously design works of architecture.

(g) In view of the above considerations, it seems that the replacement of the architect by machines will be unrealistic in coming decades.

It seems that opinions coinciding with the above observation prevail among those presented in this paper. While usually more definitive, the no votes are nevertheless partly expressed by people who have never used computers, if only because of the times in which they lived. Individuals who are professionally involved in information technology are more likely to express the opinion that, however, in the future, algorithms will be refined enough to be able to replace humans in the design process. They see this opportunity primarily in the development of technologies such as machine learning and artificial intelligence. Computers that base their architecture on living matter, such as DNA or quantum computers, will get completely new capabilities. In 2009, In a Scientific American article, Martin Campbell-Kelly wrote that "no one knows what the computers of 50 years hence will look like. Perhaps their abilities will surpass even the powers of the minds that created them" [58] (p. 8). Such a scenario cannot be ruled out especially since "the pace of change seems likely to accelerate as a result of digitalisation and advances in 'frontier technologies' such as artificial intelligence (AI), robotics, biotechnology, and nanotechnology (SDGs)" [30] (p. 3). However, even if computers do, in fact, eliminate architects in the future, it is still worth listening to the voices of the present and past skeptics. Sometimes, they also express concerns about the future of the human race in the clash with the growing role of computers or even about losing control over our lives. Those involved in computer technology should also take these voices into account and program computers with humility in such a way that they are a help to people, not a threat. It seems that due to the complex and multi-criteria nature of the architectural profession, replacing humans with machines will not be possible in the coming decades. However, it is likely that, eventually, technological developments will allow it. Until then, they should complement their work, which - at least for the time being-accelerates it and achieves greater and sometimes also innovative design capabilities.

Author Contributions: Conceptualisation, J.K. and P.Z.; methodology, J.K. and P.Z.; software, J.K. and P.Z.; validation, J.K. and P.Z.; investigation, P.Z.; resources, P.Z.; data curation, P.Z.; writingoriginal draft preparation, J.K. and P.Z.; writing-review and editing, J.K. and P.Z.; visualisation, P.Z.; supervision, P.Z.; project administration, P.Z.; funding acquisition, J.K. and P.Z. All authors have read and agreed to the published version of the manuscript.

Funding: This research was funded from statutory funds of the Poznan University of Technology, Faculty of Architecture. Funds number: 0111/SBAD/0407.

Institutional Review Board Statement: Not applicable.

Informed Consent Statement: Not applicable.

Data Availability Statement: Data sharing not applicable.

Conflicts of Interest: The authors declare no conflict of interest. 


\section{References}

1. Avermaete, T.; Teerds, H. The Roles of the Architect Toward a Theory of Practice. In The Role of the Architect, 1st ed.; Frausto, S., Ed.; Delft University of Technology: Delft, The Netherlands, 2016; pp. 7-11.

2. Tobias, M. Roles and Reponsibilities of Architects in Construction Projects. Available online: https://www.ny-engineers.com/ blog/architects-in-construction-projects (accessed on 11 July 2021).

3. Rosiak, Ł. Mission of Architect in Participation Design. Space 2018, 36, 33-48. [CrossRef]

4. Jutraz, A.; Zupancic, T. The role of architect in interdisciplinary collaborative design studios. Theory Pract. Spat. Plan. 2014, 2, 34-42. [CrossRef]

5. Can Computers Design Buildings? What Automation Means to Architects. Available online: https://www.geospatialworld.net/ article/can-computers-design-buildings-what-automation-means-to-architects/ (accessed on 28 March 2021).

6. Mukkavaara, J.; Sandberg, M. Architectural design exploration using generative design: Framework development and case study of a residential block. Buildings 2020, 10, 201. [CrossRef]

7. Eastman, C.; Teicholz, P.; Sacks, R.; Liston, K. BIM Handbook: A Guide to Building Information Modeling for Owners, Managers, Designers, Engineers, and Contractors, 1st ed.; John Wiley Sons, Inc.: Hoboken, NJ, USA, 2008; p. 13.

8. Neely, D. The Evolution of Building Information Modeling: BIM 1-2-3. Available online: https://www.cmdgroup.com/marketintelligence/articles/the-evolution-of-building-information-modeling-bim-1-2-3/ (accessed on 13 July 2021).

9. Deutsch, R. BIM and Integrated Design: Strategies for Architectural Practice, 1st ed.; John Wiley Sons, Inc.: Hoboken, NJ, USA, 2011; p. 6 .

10. Bonenberg, W.; Kapliński, O. The architect and the paradigms of sustainable development: A review of dilemmas. Sustainability 2018, 10, 100. [CrossRef]

11. Kapliński, O.; Bonenberg, W. Architecture and engineering: The Challenges-Trends—Achievements. Buildings 2020, 10, 181. [CrossRef]

12. Schumacher, P. Design Parameters to Parametric Design. In The Routledge Companion for Architecture Design and Practice: Established and Emerging Trends, 1st ed.; Kanaani, M., Kopec, D., Eds.; Routledge/Taylor and Francis: New York, NY, USA, 2016 ; p. 1.

13. Khabazi, M. Algorithmic Modelling with Grasshopper. 2009. Available online: http://download.mcneel.com/s3/mcneel/ grasshopper/1.0/docs/en/AlgorithmicModelling.pdf (accessed on 29 April 2021).

14. Bidgoli, A.; Veloso, P. DeepCloud. Arcadia 2018: Recalibration. On imprecision and infidelity. In Proceedings of the 38th Annual Conference of the Association for Computer Aided Design in Architecture, Mexico City, Mexico, 18-20 October 2018; pp. 6-7.

15. LEAD Tops YEZO Retreat with Massive Wooden Roof Shell in Japan. Available online: https://www.designboom.com/ architecture/yezo-retreat-laboratory-for-explorative-architecture-design-01--06--21/ (accessed on 29 March 2021).

16. Frey, C.B.; Osborne, M.A. The future of employment: How susceptible are jobs to computerisation. Technol. Forecast. Soc. Chang. 2017, 114, 14-58. [CrossRef]

17. Abu-Mostafa, Y.S. Machines that think for themselves. Sci. Am. 2012, 7, 81. [CrossRef]

18. Shan, W. Development of Graphic Design Based on Artificial Intelligence. J. Phys. Conf. Ser. 2020, 1533, 032022. [CrossRef]

19. Pham, D.T.; Tacgin, E. Techniques for Intelligent Computer-Aided Design. In Artificial Intelligence in Design, 1st ed; Pham, D.T., Ed.; Springer: London, UK, 1991; pp. 15-24.

20. Adio-Moses, D.; Asaolu, O.S. Artificial Intelligence for Sustainable Development of Intelligent Buildings. Conference Paper. Available online: https://www.researchgate.net/profile/David-Adio-Moses/publication/299437528_artificial_intelligence_for_ sustainable_development_of_intelligent_buildings/links/5750224508aefe968db72311/artificial-intelligence-for-sustainabledevelopment-of-intelligent-buildings.pdf (accessed on 13 July 2021).

21. Kroner, W.M. An intelligent and responsive architecture. Autom. Constr. 1997, 6, 381-393. [CrossRef]

22. Zumthor, P. Thinking Architecture, 2nd ed.; Birkhauser: Basel, Switzerland, 2006; pp. 21-65.

23. Juhani Pallasmaa: Architekt Nie Musi Być Perfekcjonistą. Available online: https://krakow.wyborcza.pl/krakow/1,42699,2132 8335,juhani-pallasmaa-architekt-nie-musi-byc-perfekcjonista.html (accessed on 10 April 2021).

24. Meltzer, T. Robots Doctors, Online Lawyers and Automated Architects: The Future of The Professions? Available online: https:/ / www.theguardian.com/technology/2014/jun/15/robot-doctors-online-lawyers-automated-architects-futureprofessions-jobs-technology (accessed on 14 July 2021).

25. Autodesk University: Automation and the Future of Work. Available online: https://www.autodesk.com/autodesk-university/ article/ Automation-and-Future-Work-2018 (accessed on 14 July 2021).

26. Grosz, E.A. Architecture from the Outside: Essays on Virtual and Real Space, 1st ed.; The MIT Press Cambridge: London, UK, 2001; p. 171.

27. Will Architects and Engineers be Replaced by Robots? Available online: https://academy.archistar.ai/will-architects-andengineers-be-replaced-by-robots (accessed on 30 March 2021).

28. Wasilkowska, A. Zdestabilizować Ściany. In That Something on the Horizon. Architecture of the 21st Century, 1st ed.; Światkowska, B., Ed.; Fundacja Bęc Zmiana: Warsaw, Poland, 2011; pp. 356-357.

29. de Graaf, R. Cztery Ściany i Dach. Złożona Natura Prostej Profesji, 1st ed.; Instytut Architektury, Nardowy Instytut Architektury i Urbanistyki Kraków-Warszawa: Warsaw, Poland, 2019; pp. 25-95.

30. Technology and Innovation Report 2021. Catching Technological Waves. Innovation with Equity, 1st ed.; United Nations Publications: New York, NY, USA, 2021; pp. 3-38. 
31. Gałazkiewicz, I. (Ed.) Technology will not substitute thinking. MOOMOO. In Awangarda Jutra?/Mapa 013, 1st ed.; Centrum Architektury i Wzornictwa Wyższej Szkoły Sztuki i Projektowania w Łodzi: Łódź, Poland, 2013; pp. $190-194$.

32. Gropius, W. Petnia Architektury, 1st ed.; Wydawnictwo Karakter: Krakow, Poland, 2014; pp. 112-129.

33. NCARB Survey Finds the Number of Architects Is Rising. Available online: https://www.architectmagazine.com/practice/ ncarb-survey-finds-the-number-of-architects-is-rising_o (accessed on 11 July 2021).

34. State of Licensure. Available online: https://www.ncarb.org/nbtn2019/state-of-licensure (accessed on 12 July 2021 ).

35. The Architectural Profession in Europe 2018. A Sector Study, Architects' Council of Europe. Available online: https://www. ace-cae.eu/fileadmin/New_Upload/7._Publications/Sector_Study/2018/2018_ACE_Report_EN_FN.pdf (accessed on 11 July 2021).

36. O'Malley, A. BIM Adoption in Europe: 7 Countries Compared. Available online: https://www.planradar.com/gb/bim-adoptionin-europe/ (accessed on 12 July 2021).

37. Wierzbicki, M. BIM-History and Trends. Conference Paper. 2011. Available online: https://www.researchgate.net/profile/ Madalina-Wierzbicki/publication/259390230_BIM_-_History_and_Trends/links/5835ec6b08aec3fe331c4bea/BIM-Historyand-Trends.pdf (accessed on 11 July 2021).

38. 9 Incredibly Famous Architects Who Didn't Possess an Architecture Degree. Available online: https://www.archdaily.com/8738 50/9-incredibly-famous-architects-who-didnt-possess-an-architecture-degree (accessed on 29 March 2021).

39. Drew, P. Tadao Ando. Church on the Water. Church of the Light. In Places of Worship, 1st ed.; Phaidon Press Limited: London, UK, 1999; p. 131.

40. Ingarden, K. From Architecture without architects to architecture after architects. Tech. Trans. 2019, 8, 23. [CrossRef]

41. Deutsch, R. Superusers: Design Technology Specialists and the Future of Practice, 1st ed.; Routledge: London, UK, 2019; pp. 11-12, 19-20.

42. Kurt, D.E. Artistic Creativity in Artificial Intelligence, 1st ed.; Radboud University: Nijmegen, The Netherlands, 2018 ; pp. 18-77.

43. Kozaczko, M. Kompozycja spoista. Balans czynników jakościowych i ilościowych. Zesz. Nauk. Politech. Poznańskiej. Archit. Urban. 2010, 22, 88 .

44. Carlie, J. Using Data to Improve the Built Environment, Lecture within KeenCon 2014. Available online: https:/ / vimeo.com/10 7291814 (accessed on 29 March 2021).

45. Cichocka, J.; Browne, W.N. Multi criteria optimization in architectural design: Goal-oriented methods and computational morphogenesis. In Shapes of Logic. Everything What Surround Us Can Be Described, 1st ed.; Symonowicz, J., Nisztuk, M., Pakowska, M., Eds.; Oficyna Wydawnicza Politechniki Wrocławskiej: Wrocław, Poland, 2016; p. 113.

46. Nidal, I.A.D. The Impact of Artificial Intelligence on the Future of Architecture Architects. The Revolution of Artificial Intelligence. Available online: https://www.researchgate.net/publication/349917109_The_Impact_of_Artificial_intelligence_on_the_future_ of_architecture_architects_The_Revolution_of_Artificial_Intelligence (accessed on 12 July 2021).

47. Dąbrowska-Budziło, K. Genius Loci, jako potencjalne źródło inspiracji dla kształtowania krajobrazu. Niematerialne Wartości Kraj. Kult. Pr. Kom. Kraj. Kult. 2011, 15, 228.

48. Marr, B. Can Machines and Artificial Intelligence Be Creative? Available online: https://www.forbes.com/sites/bernardmarr/20 20/02/28/can-machines-and-artificial-intelligence-be-creative/ (accessed on 29 March 2021).

49. Spacey, J. What is Recursive Self-Improvement? Available online: https://simplicable.com/new/recursive-self-improvement (accessed on 12 April 2021).

50. Gu, N.; Behbahani, P.A. A critical review of computational creativity in built environment design. Buildings 2021, 11, 29. [CrossRef]

51. Deamer, P. Architecture and Labor, 1st ed.; Routledge: New York, NY, USA, 2020; p. 17.

52. Kuipers, B. Human-like morality and ethics for robots. In AAAI Workshop AI, Ethics, and Society: Technical Report WS-16-02; 2016; pp. 98-103. Available online: https://www.aaai.org/ocs/index.php/WS/AAAIW16/paper/view/12581/12351 (accessed on 1 August 2021).

53. Arkin, R.C.; Wagner, A.R. Moral decision making in autonomous systems: Enforcement, moral emotions, dignity, trust and deception. Proc. IEEE 2012, 3, 1-46. [CrossRef]

54. Asimov, I. I, Robot, 1st ed.; Gnome Press: New York, NY, USA, 1950.

55. Zinn, M.; Khatib, O.; Roth, B.; Salisbury, K. Playing it safe: A new concept for human-friendly robot design. IEEE Robot. Autom. Mag. 2004, 6, 13-21.

56. Tsafestas, S.G. Roboethics: Fundamental concepts and future prospects. Roboethics 2018, 9, 148. [CrossRef]

57. Sandberg, A.; Bostrom, N. Whole Brain Emulation. A Emulation: A Roadmap, Technical Report 2008-3, 1st ed.; Oxford University: Oxford, UK, 2008; p. 81.

58. Campbell-Kelly, M. Origin of Computing. Sci. Am. 2009, 9, 62-69. [CrossRef] [PubMed] 